\title{
Morbidities in the Glass Factory Workers of Central India.
}

\author{
Kishor P Brahmapurkar ${ }^{1}$, Ashok G. Lanjewar ${ }^{2}$, Sanjay P Zodpey ${ }^{3}$, Vaishali K \\ Shrote (Brahmapurkar) ${ }^{4}$, Q.H.Khan ${ }^{5}$, Gautam M Khakse ${ }^{6}$, Teeku Sinha ${ }^{7}$, \\ Vivekanand C. Giri $^{8}$, P.K. Shrivastava ${ }^{9}$, V.K.S.Chauhan ${ }^{10}$ \\ ${ }^{I}$ (Department of Community Medicine, Lt .B R K M Government Medical College, Jagdalpur, Bastar [C.G.] India) \\ ${ }^{2}$ (Department of Community Medicine, Raichur Institute of Medical Sciences, Raichur [Karnataka], India) \\ ${ }^{3}$ (Public Health Foundation India [PHFI] New Delhi, India) \\ ${ }^{4}$ (Department of Community Medicine, Lt. B R K M Government Medical College, Jagdalpur, Bastar [C.G.] India) \\ ${ }^{5}$ (Department of Community Medicine, Lt. B R K M Government Medical College, Jagdalpur, Bastar [C.G.] India) \\ ${ }^{6}$ ( Department of Preventive and Social Medicine, S. V. N. Government Medical College, Yavatmal [M.S] India) \\ ${ }^{7}$ (Department of Community Medicine, Lt. B R K M Government Medical College, Jagdalpur, Bastar [C.G.] India) \\ ${ }^{8}$ ( Department of Epidemiology and Statistics, Central Leprosy Teaching and Research Institute, Chengalpattu-Tamil Nadu, \\ India.) \\ $9 \& 10$ (Department of Community Medicine, Lt. B R K M Government Medical College, Jagdalpur, Bastar [C.G.] India)
}

\begin{abstract}
Introduction: The health hazard of glass factory has been enlisted in ILO encyclopedia. Morbid conditions in glass factory workers are injuries, heat exhaustion, respiratory morbidity, ophthalmic morbidity, nephrolithiasis etc.

Objective: To estimate the prevalence of morbidity in the glass factory workers and compare it with comparison group.

Materials and methods: Cross-sectional study with comparison group, which was matched for age, sex and socio-economic status, unexposed to similar working environment from adjacent area. The Glass Factory is situated at Kamptee Road, Nagpur. 263 workers were studied along with 263 comparison group. Interview technique, general observation was used for data collection by using Pre-designed Proforma. Sampling design was Convenience sampling Technique. Statistical analysis was done with Epi Info 2002.

Results: Total morbidities were 442 and 153 in the workers and in the comparison group respectively. Mean no. of morbidity in the worker was 1.7 with SD 0.94 and in the comparison group it was 0.6 with SD 0.83. The difference was statistically significant $[Z=13.76, p<0.01$, highly significant]. Of the total morbidities i.e. 442 in workers, injury constituted 251 (56.9\%). Incised injury $156(59.3 \%)$ in the workers and $32(12.2 \%)$ in the comparison group.

Conclusion: Prevalence of injury and effect of environment in the workers of Glass Factory was more than subjects in comparison group.

Key Words: Glass factory, Injuries, Morbidity, workers.
\end{abstract}

\section{Introduction}

Scientific progress has made life more comfortable; but there exists the potential for permanent anatomical or physiological damage due to hazards especially among industrial workers. Traumatic occupational injuries lead to 10,000 deaths among workers annually. The International Labour Organization has observed that an estimated 50 million work related injuries occur every year or 160000 every day.

Various hazards in the glass industry as ILO encyclopedia are [1]:

1. Accidents - during handling of glass in flat industry. In others burns are most frequent.

2. Silica - natural sand is used from which the fine particles have been removed during washing and it is not a cause of silicosis. Fine sand because of ease of melting is sometimes used, can produce hazardous airborne siliceous dust.

3. Lead - In colouring of glass and can cause health hazard.

4. Alkaline dust - Soda ash/ potash can cause nasal ulceration or perforation. Also it acts as skin irritant and can cause caustic burns.

5. Other raw materials - e.g. arsenic can cause skin and lung cancer and also act as skin irritant.

6. Fuels and products of combustion - fuel oils for firing can cause scrotal carcinoma during skin contact. Oil fired process - $\mathrm{SO}_{2}$ is produced can cause respiratory morbidity.

7. Miscellaneous hazards: A common method of obscuring glass by application of hydrochloric acid can cause burns and fume hazard.

8. Heat and radiant energy - Black bulb temp $120-160^{\circ} \mathrm{C}$ can up to $-200^{\circ} \mathrm{C}$ causes heat stress.

9. Glass blowing - deformity of cheeks, damage to mouth and teeth, emphysema and chancre of lips by multiple use of same apparatus. 
10. Heat cataract: Posterior polar cataract; secondary to heat effect on iris and ciliary body.

11. Noise $-100 \mathrm{~dB}$ - produced by high-pressure air-cooling jets.

In the lower income countries such as those of South Asia and Africa, injuries are one of the leading causes of adult mortality and a major contributor to disability. The primary concern of occupational health and safety is to study the dynamic inter-relationship between work and health and the attainment of the best balance between them.

Intense hot environments are prevalent in the iron, steel, glass and ceramics units, rubber, foundries, coke ovens, mines and many other industries.

Injuries are common in glass factory workers i.e. cuts, burns etc. The health hazards of glass factory have been enlisted in ILO encyclopedia.

Morbid conditions in glass factory workers are injuries, respiratory morbidity, ophthalmic morbidity, nephrolithiasis etc.

It is necessary to carry out research for the prevention of occupational accidents and ill health caused by harmful factors in the workplace. Equally important is the creation of the working condition and an environment that maintains and promotes the health of workers.

Very few studies are there dealing with the morbidities of glass factory workers. It was with this background that the present study was undertaken to find out morbidities in glass factory workers.

In the Glass factory the processes and materials involved were as follows:

Raw section

\section{(Cullet 95\%)}

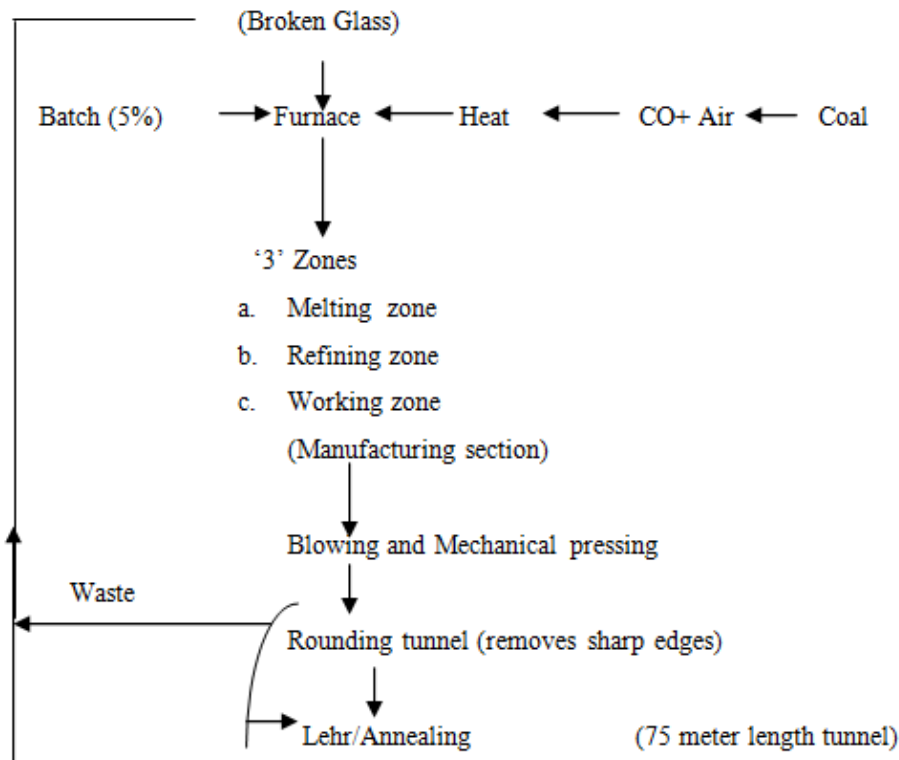

(Controlled coding)

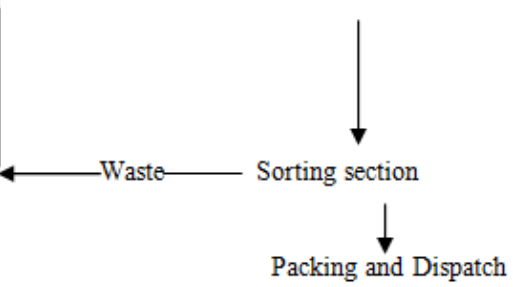

At cool end - Normal temp.

$' 45$ ' min required to pass from hot end

to cool end of lehr tunnel.

"The processed and materials involved."

In Glass Factory', the raw material used is $95 \%$ cullet i.e. waste glass and 5\% batch (mixture of sand, sodium and chemicals).The raw material was added to furnace (400-500 kg/hr depending upon the order). The coal is used for heat generation purpose. When all the substances in the mixture have melted the temperature of mixture is raised to around $1500^{\circ} \mathrm{C}$. The operations, involve increased heat levels and possibility of exposure of heat (radiant) to workers.

It was with this background that the present study was undertaken to compare the morbidities between the group of glass factory workers and the comparison group from general population of adjacent area not working in similar working environment. 


\section{Material And Methods}

2.1Study design: The study design was cross-sectional study with comparison group, which was matched for age, sex and socio-economic status, unexposed to similar working environment i.e. Glass Factory.

\subsection{Study Setting}

The Glass Factory is situated at Uppalwadi, Piwdi Nadi, Kamptee Road, Nagpur in the Maharashtra State (M.S.) at $12 \mathrm{~km}$. from Government Medical College, Nagpur.

Comparison group was selected from general population of adjacent area, Piwdi Nadi, Kamptee Road, Nagpur in Maharashtra.

\subsection{Study Population}

It includes workers of Glass Factory. Total number of employees of the factory was 295. After excluding the administrative staff and office employees (27), total number of workers enrolled was 268. Of the 268 workers ' 05 ' did not co-operate. Hence 263 workers were studied along with 263 comparison group. A written consent was obtained from study subjects before data collection. The worker on leave more than 15 days was exclusion criteria along with those who do not co-operate. An inclusion criterion was workers on pay roll and those giving written consent. Permission was obtained from Institutional Ethics Committee Government Medical College, Nagpur.

\subsection{Methodology}

To start with a list of glass factories was obtained from 'Sub-Regional Employees State Insurance Corporation' (E.S.I.C.) Office, Ganeshpeth, Nagpur. The Glass Factory was selected by Convenience sampling Technique for the study purpose as necessary permission to carry out the study was given by the owner and general manager of the factory and they assured co-operation for performing the study. The permission was obtained from the concern Government official i.e. Deputy Director, Industrial Safety and Health, Nagpur

The purpose of the study was discussed with the workers. The time schedule was prepared, so that workers could participate in the study conveniently.

The pilot study was carried out in the month of December 2003 with predesigned proforma. Interview technique, general observation and investigation were used for data collection.

The pilot study was carried out on 30 workers and 30 from comparison group. Depending upon the findings of the pilot study, suitable corrections were made in the proforma and the proforma was modified.

The predesigned, pretested proforma was used for data collection. The data was collected in the following manner.

After collecting data for 30 to 40 workers, the comparison group was selected from the community area of Piwdi Nadi. Initially age and sex matching was done and then matching was done for socioeconomic status. The data was collected on the similar proforma, which was used in workers.

\section{Statistical Analysis}

Percentages, Chi-square test, Z test were applied for statistical analysis purpose with Epi Info 2002.

TABLE NO.1

Morbidity in the study subjects

\begin{tabular}{lccc}
\hline \multirow{2}{*}{ Morbidity } & \multicolumn{2}{c}{ Study subjects } & Total \\
& Norkers & Comparison group & No. (Percent) \\
\hline Present & $244(92.8)$ & $103(39.2)$ & $347(66.0)$ \\
Absent & $019(7.2)$ & $160(60.8)$ & $179(34.0)$ \\
Total & $263(100)$ & $263(100)$ & $526(100)$ \\
\hline
\end{tabular}

Morbidity (worker vs. comparison group)

$\chi^{2}=165.9, \mathrm{df}=1, \mathrm{P}<0.0001$, H.S.

TABLE NO.2

Distribution of morbid conditions in the study subjects

\begin{tabular}{|c|c|c|c|c|c|}
\hline \multirow{4}{*}{ ICD code } & \multicolumn{5}{|c|}{ Study subjects } \\
\hline & \multirow[t]{3}{*}{ Morbid Condition } & & \multirow{3}{*}{$\begin{array}{c}\text { Comparison } \\
\text { Group } \\
\text { No. }(\%)\end{array}$} & \multirow[t]{3}{*}{$\chi^{2}$} & \multirow[t]{3}{*}{$\mathrm{P}$ value } \\
\hline & & Worker & & & \\
\hline & & No. $(\%)$ & & & \\
\hline \multicolumn{6}{|l|}{ INJURY } \\
\hline W25 & Incised injury (Cuts) & $156(59.3)$ & $32(12.2)$ & 127.3 & $<0.001$, HS \\
\hline T 30.1 & Burns & $73(27.7)$ & $0(0.0)$ & 84 & $<0.001$, HS \\
\hline $\mathrm{T} 14$ & Blunt injury & $08(3.0)$ & $20(7.6)$ & 4.5 & $<0.05, \mathrm{~S}$ \\
\hline Т 140 & Abrasion & $08(3.0)$ & $52(19.8)$ & 23.1 & \\
\hline
\end{tabular}


Morbidities In The Glass Factory Workers Of Central India.

\begin{tabular}{|c|c|c|c|c|c|}
\hline T 141 & Laceration & $06(2.3)$ & $0(0.0)$ & & $<0.001, \mathrm{HS}$ \\
\hline \multicolumn{6}{|c|}{ Effect of hot environment } \\
\hline Т 67.5 & Heat exhaustion & $74(28.1)$ & $04(1.5)$ & 71.7 & $<0.001, \mathrm{HS}$ \\
\hline Т 67.2 & Heat cramps & $58(22.0)$ & $02(0.8)$ & Test not & \\
\hline Т 67.0 & Heat hyperpyrexia & $07(2.6)$ & $0(0.0)$ & applied & \\
\hline \multicolumn{6}{|c|}{ Respiratory System } \\
\hline J 06.9 & $\begin{array}{l}\text { Upper Respiratory tract infection } \\
\text { Lower Respiratory tract infection }\end{array}$ & $14(5.3)$ & $09(3.4)$ & & \\
\hline J 22 & Bronchial asthma & $06(2.2)$ & $04(1.5)$ & 0.74 & $>0.1, \mathrm{NS}$ \\
\hline J 45.9 & & $01(0.4)$ & $02(0.8)$ & & \\
\hline \multicolumn{6}{|c|}{ Cardiovascular system } \\
\hline I 10 & Hypertension & $07(2.7)$ & $08(3.0)$ & $x$ & \\
\hline I 25.9 & Ischaemic Heart Disease & $0(0.0)$ & $02(0.8)$ & 0.33 & $>0.1, \mathrm{NS}$ \\
\hline \multicolumn{6}{|c|}{ Eye and adnexa } \\
\hline Н 52.7 & Refractive error & $18(6.8)$ & $15(5.7)$ & 0.0002 & $p>0.5$ \\
\hline \multicolumn{6}{|c|}{ Ear and adnexa } \\
\hline Н 83.9 & Chronic suppurative otitis media & $02(0.8)$ & $0(0.0)$ & $\begin{array}{l}\text { Test not } \\
\text { applied }\end{array}$ & - \\
\hline \multicolumn{6}{|c|}{ Gastrointestinal system } \\
\hline K 59.0 & Constipation & $03(1.1)$ & $02(0.8)$ & $\begin{array}{l}\text { Test not } \\
\text { applied }\end{array}$ & - \\
\hline \multicolumn{6}{|l|}{ Skin } \\
\hline L 23.5 & Allergic contact dermatitis & $01(0.4)$ & $0(0.0)$ & $\begin{array}{l}\text { Test not } \\
\text { applied }\end{array}$ & - \\
\hline \multicolumn{6}{|c|}{ Endocrine system } \\
\hline \multirow[t]{2}{*}{ E 14} & Diabetes mellitus & $0(0.0)$ & $01(0.4)$ & $\begin{array}{l}\text { Test not } \\
\text { applied }\end{array}$ & - \\
\hline & Total & 442 & 153 & & \\
\hline
\end{tabular}

Mean no. of morbidity per worker $=1.7$, SD 0.94

Mean no. of morbidity per subject in comparison group $=0.6, \mathrm{SD}=0.83$

$\mathrm{Z}=13.76, \mathrm{p}<0.01$, highly significant.

TABLE NO.3

Distribution of study subjects according to the number of morbid conditions

\begin{tabular}{|c|c|c|c|c|}
\hline $\begin{array}{c}\text { Number of morbid } \\
\text { condition }\end{array}$ & $\begin{array}{c}\text { Workers } \\
(\mathrm{n}=263) \\
\text { No. (Percent) }\end{array}$ & $\begin{array}{l}\text { subjects } \\
\text { Comparison group }(\mathrm{n}=263) \\
\quad \text { No. (Percent) }\end{array}$ & $\mathrm{Z}$ & $P$ value \\
\hline One & $102(38.8)$ & $55(20.9)$ & 4.5 & $\mathrm{P}<0.01, \mathrm{H} . \mathrm{S}$. \\
\hline Two & $95(36.1)$ & $44(17.1)$ & 5.1 & $\mathrm{p}<0.01$ H.S. \\
\hline Three & $40(15.2)$ & $02(0.8)$ & & \\
\hline > Three & $07(2.7)$ & $01(0.4)$ & 6.9 & $\mathrm{P}<0.01$ H.S. \\
\hline
\end{tabular}

\section{Results}

Out of 526 study subjects (263 workers and 263 comparison group) males constituted $244(92.8 \%)$ while females constituted $19(7.2 \%)$ in both group i.e. Workers and Comparison Group. Mean age \pm Standard Deviation for workers was 29.3 (years) \pm (9.8) and for Comparison group it was 30.0 (years) \pm (9.9). The mean length of exposure in glass factory workers was 8.2 year with standard deviation 8.3 years and range 01 months -42 years

Table 1 reveals that, 244 (92.8\%) workers had one or other morbid condition and in comparison group $103(39.2 \%)$ had one or other morbid condition. The difference was statistically significant. $\left[\chi^{2}=165.9, \mathrm{df}=1\right.$, $\mathrm{p}<0.0001$, highly significant].

The distribution of morbid conditions in the study subjects was summarized in Table 2; it reveals that total morbidities were 442 and 153 in the workers and in the comparison group respectively. Mean no. of morbidity in the worker was 1.7 with SD 0.94 and in the comparison group it was 0.6 with SD 0.83 . The difference was statistically significant $[\mathrm{Z}=13.76, \mathrm{p}<0.01$, highly significant $]$.

Of the total morbidities i.e. 442 in workers, injury constituted 251 (56.9\%). Incised injury $156(59.3 \%)$ in the workers and $32(12.2 \%)$ in the comparison group. The difference was statistically significant $\left[\chi^{2}=127.3\right.$, $\mathrm{df}=1, \mathrm{p}<0.001$, highly significant $]$.

Health effect of hot environment found that, $139(31.4 \%)$ and $6(4 \%)$ in the workers and comparison group respectively. Heat exhaustion was observed in $74(28.1 \%)$ and $4(1.5 \%)$ in workers and comparison group respectively. The difference was statistically significant $\left[\chi^{2}=71.7, \mathrm{df}=1, \mathrm{p}<0.001\right.$, highly significant $]$. 
Among respiratory morbidity, Upper Respiratory Tract Infection ,14 (5.3\%) and $9(3.4 \%)$ in workers and comparison group. In cardiovascular system, hypertension $07(2.7 \%)$ and $08(3.0 \%)$ and IHD $0(0.0 \%)$ and $2(0.8 \%)$ in the workers and comparison group respectively. The difference was not statistically significant $\left[\chi^{2}=0.33, p>0.1\right.$, not significant $]$.

When distribution of study subjects according to the number of morbid condition was studied as in Table 3, it was found that one morbid condition was present in $102(38.8 \%)$ and $55(20.9 \%)$ in the worker and comparison group respectively. The difference was statistically significant $[\mathrm{Z}=4.5, \mathrm{p}<0.01$, highly significant $]$. Two morbid conditions were present in $95(36.1 \%)$ and $44(17.1 \%)$ in the worker and comparison group respectively. The difference was statistically significant $[Z=5.1, p<0.01$, highly significant $]$. As frequency was less in more than 3 morbid conditions, it was clubbed with the three morbid conditions i.e. three and more than three morbid conditions. There were $47(17.9 \%)$ and $3(1.2 \%)$ in the worker and comparison group respectively having three or more than three morbid conditions. The difference was statistically significant $[Z=6.9, p<0.01$, highly significant].

\section{Discussion}

Bazroy et al (2000) studied magnitude of injuries in glass bottle manufacturing plant[2]. They found cuts and laceration $50.1 \%$, injuries to eye $30 \%$, sprains $8 \%$ and burns $7.1 \%$. In our study we found cuts $(59.3 \%$ ) in workers and burns $27.7 \%$ as a direct effect of heat exposure workers [3].

Gordon et al (1998) found consistent syndrome of work related eye, nose and throat irritation in

In respiratory morbidity Srivastava et al (1988) studied pulmonary diseases due to multimetal exposure and found $7.2 \%$ of glass bangle workers had radiologic abnormalities and this was attributed to long exposure to dust and fumes of different metals in low doses [4].

Lydhal E et al (1984)studied infrared radiation and cataract and found that statistically significant increase of aphakia and all types of cataract, subcapsular, cuneiform and nuclear compared to comparison group in age group of 70 years and older [5] and it was concluded that occupational infrared radiation exposure of glass workers accelerates the development of senile changes in lens.

Borghi et al (1993) found $8.5 \%$ prevalence of nephrolithiasis in workers [6] as compared to $2.4 \%$ in comparison group $[\mathrm{p}=0.03]$.

In the present study, the effect of heat stress, Heat exhaustion (28.1\%), heat cramps $(22.0 \%)$, Heat hyperpyrexia $(2.6 \%)$ were reported indicating significant occurrence of heat stress among glass factory workers., similar findings of exposure to heat stress Patel HarshadC et al, 2006 [7] was noted. Heat exhaustion $48(18.3 \%)$; heat cramps $16(6.1 \%)$ and heat pyrexia $11(4.2 \%)$ were reported among firefighters. $15.9 \%$ of workers in Iron industry and 20.3\% Ceramic workers experienced heat cramps.(Vulnerability to Heat Stress: Scenario in Western India WHO,2009)[8].

\section{Conclusion}

In the present study the prevalence of injury and effect of environment in the workers of Glass Factory was more than the subjects in comparison group.

\section{Recommendation}

1. To provide foot wears as personal protective devices to the workers.

2. To promote use of personal protective devices.

\section{References:}

[1]. ILO Encylopedia of Occupational Health and Safety, Vol. I,. $3^{\text {rd }}$ (revised) ed., 1983 ILO : $966-970$.

[2]. Bazroy J, Gautam Roy, Ajit Sahai, MB Soudarssanare. Magnitude and risk factors of injuries in a glass bottle manufacturing plant. J Occup Health $2003 ; 45: 53-59$.

[3]. Gordon SB, Curran AD, Fishwick D, Morice AH, Howard P. Respiratory symptoms among glass bottle workers - cough and airways irritancy syndrome? Occup Med (Lond) 1998 ; 48 (7) : 455 - 59. [Abstract from Medline]

[4]. Srivastava AK, Gupta BN. Ophthalmic morbidity in glass workers. Ind J Indus Med $1988 ; 34$ (4) : 161 - 65.

[5]. Lydhal E. Infrared radiation and cataract. Acta Ophthalmol 1984; $16: 61$ - 63 [Abstract from Medline].

[6]. Borghi L, Meschi T, Amato F, Nevarini A, Romanelli A, Cigala F. Hot occupation and nephrolithiasis. J Urol 1993 ; 150 (6) : 1757 60 [Abstract from Medline].

[7]. Patel HarshadC, Rao NelloreMohan, Saha Asim. Indian Journal of Occupational and Environmental Medicine, Vol. 10, No. 3, September-December, 2006, pp. 121-123

[8]. Vulnerability to Heat Stress: Scenario in Western India WHO APW No. SO AMS 6157206 .2009. [Cited 2011 August 29] Availablefrom:URL:http://www.whoindia.org/.../Climate_Change_Vulnerability_to_Heat_Stress_Scenario_in_Western_India.pdfAdo 